\title{
Desempenho de bovinos de corte mantidos em pastagem de capim- marandu submetidos a diferentes estratégias de suplementação no período das águas e da seca
}

\author{
Roberta Carrilho Canesin², Telma Teresinha Berchielli ${ }^{*}$, Pedro de Andrade ${ }^{3}$, Ricardo \\ Andrade Reis ${ }^{3^{*}}$
}

\footnotetext{
1 Parte da dissertação de Mestrado da primeira autora. Projeto financiado pela FAPESP.

2 Programa de Pós-Graduação em Zootecnia da FCAVIUNESP - Jaboticabal, SP. Bolsista do CNPq.

3 Departamento de Zootecnia - FCAVIUNESP - Jaboticabal, SP.

*Pesquisador do CNPq.
}

RESUMO - Este trabalho foi realizado com o objetivo de avaliar o ganho de peso de bovinos mantidos em pastagens de Brachiaria brizantha cv. Marandu submetidos a três estratégias de suplementação no período das águas e da seca de 2003 e águas de 2004. Os tratamentos consistiram da suplementação diária (SD), em dias alternados (DA) e de segunda à sexta-feira (SF). Foram utilizados 24 bovinos mestiços com peso inicial de $230 \mathrm{~kg}$. Os animais foram pesados individualmente sem jejum, em intervalos de 28 dias. O delineamento adotado foi o inteiramente casualizado, com três tratamentos e oito repetições. Não houve diferença no ganho de peso dos animais, sendo obtidos valores médios de 0,$76 ; 0,71$ e $0,74 \mathrm{~kg} /$ dia no período das águas de 2003, de 0,57;0,51 e 0,54 kg/dia na seca do mesmo ano e de 0,61;0,62 e 0,57 kg/dia no período das águas de 2004 nos tratamentos SD, DA e SF, respectivamente. A redução na freqüência de suplementação pode representar uma opção para o produtor visando à redução dos custos do fornecimento da alimentação, pois permite maior racionalização da mão-de-obra na propriedade e não afeta o desempenho animal.

Palavras-chave: frequiência de suplementação, forragem tropical, ganho de peso, pastejo

\section{Performance of beef steers grazing Brachiaria brizantha cv. Marandu and receiving different supplementation strategies during the rainy and dry seasons}

\begin{abstract}
The objective of this study was to evaluate weight gain of beef steers grazing Brachiaria brizanthacv. Marandu and receiving one out of three different supplementation strategies during the rainy season of 2003 and the dry and rainy seasons of 2004. Twenty-four crossbreed steers averaging $230 \mathrm{~kg}$ of initial body weight were assigned to one of the following supplementation strategies: daily supplementation (DS), supplementation in alternated days (AD), or supplementation from Monday to Friday (MF) in a completely randomized design ( 8 replicates/treatment). Animals were individually weighted with no fasting every 28 days. There were no differences in weight gain among the different supplementation strategies averaging $0.76,0.74$, and $0.71 \mathrm{~kg} /$ day during the rainy season of $2003 ; 0.61,0.62$, and $0.57 \mathrm{~kg} /$ day during the dry season of 2004 ; and $0.57,0.54$, and $0.51 \mathrm{~kg} /$ day during the rainy season of 2004 , respectively, for DS, AD and MF treatments. It can be concluded that reducing supplementation frequency may decrease feeding and labor costs with no negative impact on animal performance.
\end{abstract}

Key Words: grazing, supplementation frequency, tropical forage, weight gain

\section{Introdução}

A pecuária de corte é uma atividade de grande importância social e econômica no Brasil. Os cenários, tanto interno quanto externo, apontam para o fortalecimento dessa atividade, seja como produtora de alimento de alta qualidade seja como geradora de divisas. Entre as vantagens da pecuária nacional, destacam-se a competitividade econômica, a produção de carne sob condições de ambientes naturais e a tendência de demanda dos mercados mais exigentes. Diante dessas vantagens, a bovinocultura está passando de uma atividade extrativista e extensiva à utilização intensiva de tecnologia e à melhor capacidade de gerenciamento para maior eficiência ao longo de toda a cadeia produtiva (Zervoudakis, 2000).

Uma vez que as pastagens constituem a base da alimentação de rebanhos estabelecidos nas regiões tropicais, o desempenho animal é obtido a partir da interação forragem disponível $\times$ consumo $\times$ digestão $\times$ exigências nutricionais, 
que pode ser satisfatório ou não no sistema de produção. Diante de um desempenho não satisfatório, é necessária a suplementação da dieta dos animais, que deve ser conveniente do ponto de vista técnico-econômico (Zervoudakis et al., 2002).

Contudo, um dos fatores determinantes da produção animal em sistema de suplementação em pastagem consiste na definição dos objetivos principais desta suplementação. Conseqüentemente, devem ser estabelecidas estratégias de fornecimento de nutrientes que viabilizem, os padrões de crescimento pretendidos no sistema de produção. Neste contexto, o fornecimento de nutrientes via suplementação pode possibilitar desempenho diferenciado aos animais, desde a simples manutenção de peso, passando por ganhos moderados de 200 a $300 \mathrm{~g} / \mathrm{dia}$, até ganhos de 500 a $600 \mathrm{~g} /$ dia (Paulino, 2001).

Em virtude da sazonalidade quantitativa e qualitativa das plantas forrageiras de clima tropical e das diferenças marcantes na composição bromatológica e na disponibilidade no período das águas e da seca, a meta principal da suplementação seria reduzir as deficiências nutricionais desta forragem, para estimular o consumo e a sua digestibilidade, aumentando o desempenho dos animais.

No período da seca, as forrageiras tropicais apresentam baixo valor nutritivo, com teores de PB inferiores ao mínimo de 7,0\% na MS, limitando a atividade de microrganismos. Conseqüentemente, verifica-se diminuição da digestibilidade da fração fibrosa da forragem e da produção de ácidos graxos voláteis, importantes fontes de energia para os ruminantes, além de carência protéica e energética nesse período (Minson, 1990).

A suplementação com fontes de proteína verdadeira também permite corrigir a deficiência de energia, pois promove aumento na proporção de microrganismos no rúmen $\mathrm{e}$, conseqüentemente, eleva a digestibilidade da forragem de menor qualidade e os consumos de MS e energia digestível, resultando em melhor desempenho dos animais (Reis et al., 1997).

A suplementação com proteína de baixa degradação ruminal permite a absorção de aminoácidos no intestino, resultando em efeito positivo sobre o consumo de forragem e o desempenho animal (Siebert \& Hunter, 1982), desde que haja quantidades adequadas de nitrogênio no rúmen para manter nível de amônia suficiente para a eficiente degradação da fração fibrosa.

$\mathrm{Na}$ formulação dos suplementos, devem ser incorporadas fontes de proteína de baixa degradabilidade no rúmen e, em algumas situações, fontes de alta degradabilidade (e mesmo nitrogênio não-protéico) para otimizar a ingestão, a digestão da forragem e a assimilação dos nutrientes, bem como minimizar os custos com suplemento. Contudo, para que os objetivos sejam atingidos, é necessário que o balanceamento do suplemento respeite as características da forragem disponível e do animal a ser suplementado.

Em situações em que há aumento na participação do concentrado na ração, como na terminação de bovinos em pastagem, a necessidade de distribuição diária de concentrado eleva os custos operacionais, levando pecuaristas e técnicos a buscar opções para melhorar a operacionalidade da alimentação e distribuir o suplemento com menor freqüência (intervalos de dois ou três dias), aumentando o período de pastejo e reduzindo os custos.

Resultados de pesquisa têm comprovado que os ruminantes podem ser suplementados com proteína em intervalos maiores que um dia e que os benefícios da suplementação protéica persistem após a ingestão do concentrado (Farmer et al., 2001; Bohnert et al., 2002a), o que pode ser explicado pela reciclagem da amônia absorvida no rúmen, que garante a adequada fermentação entre os períodos de fornecimento do suplemento. Os ruminantes podem ter habilidade de conservar nitrogênio por longos períodos, possivelmente por meio de mudanças na permeabilidade do trato gastrintestinal à uréia e/ou da regulação da excreção renal, mantendo o fornecimento de nitrogênio entre os períodos de suplementação com uréia (Bohnert et al., 2002b).

A redução na freqüência da suplementação protéica tem se mostrado eficiente, pois não causa prejuízos à fermentação ruminal e permite ao produtor a oportunidade de economia de tempo, de mão-de-obra e de equipamentos associados à suplementação.

Diante da grande variabilidade dos sistemas produtivos no setor pecuário brasileiro e da sensível adesão do produtor à técnica de suplementação, muitas dúvidas ainda permanecem obscuras quanto a esta prática de manejo nutricional. Há anos, os pesquisadores têm se esforçado na tentativa de equacionar integralmente a técnica de suplementação em pastagens, em decorrência da complexidade da interação solo $\times$ clima $\times$ forragem $\times$ animal $\times$ suplemento utilizado (Brito, 2004).

O objetivo neste trabalho foi avaliar o ganho de peso de bovinos em pastagem de Brachiaria brizantha recebendo suplementação nos períodos das águas e das secas, submetidos a diferentes estratégias de suplementação.

\section{Material e Métodos}

O trabalho foi realizado na Faculdade de Ciências Agrárias e Veterinárias - Unesp, Campus de Jaboticabal/SP, em área pertencente ao Departamento de Zootecnia. 
Na Tabela 1 constam os dados das condições climáticas durante o período experimental, obtidos na Estação Agroclimatológica - UNESP - Campus de Jaboticabal.

A área utilizada para o experimento possuía 15 ha cultivados com Brachiaria brizantha (Hochst) Stapf cv. Marandu e foi subdividida com cerca elétrica em cinco piquetes de 3 ha, providos de bebedouros do tipo australiano e cocho para suplementação mineral.

A suplementação aos animais foi realizada em uma instalação anexa ao curral de manejo, dotada de 24 baias individuais, todas com cocho individual e bebedouro para cada duas baias.

Foram utilizados 24 bovinos mestiços (Bos indicus $\mathrm{x}$ Bos taurus) com predominância da cruza Nelore x Holandês, machos, castrados, com 15 a 18 meses de idade e peso médio inicial de $230 \mathrm{~kg}$. Os animais foram identificados com brincos numerados e, após vermifugação, foram mantidos durante 14 dias em adaptação na pastagem de Brachiaria brizantha antes do início do experimento. Durante todo o período experimental (janeiro de 2003 a fevereiro de 2004), foram mantidos em pastejo, sendo recolhidos às baias individuais pelas manhãs (às $8 \mathrm{~h}$ ), onde foram receberam suplemento conforme a estratégia adotada. Aproximadamente às $13 \mathrm{~h} 30$, após a suplementação, os animais foram soltos nos piquetes. Nos diferentes períodos (águas e seca de 2003 e águas de 2004), não houve adaptação prévia dos animais ao suplemento.

Os valores relativos ao consumo de concentrado foram mensurados individualmente por animal por dia, a partir da quantidade oferecida e das sobras no cocho. As médias

Tabela 1 - Condições climáticas da região durante o período experimental

Table 1 - Weather conditions during the experimental period

\begin{tabular}{lcc}
\hline $\begin{array}{l}\text { Mês } \\
\text { Month }\end{array}$ & $\begin{array}{c}\text { Precipitação (mm) } \\
\text { Precipitation }(\mathrm{mm})\end{array}$ & $\begin{array}{c}\text { Temperatura média }\left({ }^{\circ} \mathrm{C}\right) \\
\text { Average temperature }\left({ }^{\circ} \mathrm{C}\right)\end{array}$ \\
\hline \multicolumn{3}{c}{2003} \\
\hline Janeiro (January) & 372,9 & 24,2 \\
Fevereiro (February) & 153,5 & 25,4 \\
Março (March) & 107,2 & 24,0 \\
Abril(April) & 124,1 & 22,6 \\
Maio (May) & 86,7 & 19,0 \\
Junho (June) & 12,3 & 20,5 \\
Julho (July) & 17,2 & 19,4 \\
Agosto (August) & 10,6 & 22,8 \\
Setembro (September) & 23,3 & 24,0 \\
Outubro (October) & 66,6 & 24,0 \\
Novembro (November) & 77,7 & 25,0 \\
Dezembro (December) & 210,2 & 24,0 \\
\hline & & 2004 \\
\hline Janeiro (January) & 423,4 & \\
Fevereiro (February) & 313,7 & \\
\hline
\end{tabular}

mensais foram obtidas a partir dos valores médios a cada 28 dias, nos mesmo dia das pesagens. Para acompanhamento da evolução do peso e cálculo de ganho diário de peso, os animais foram pesados, sem jejum, no início do período experimental (21/01/2003) e a cada 28 dias, totalizando 14 períodos experimentais.

Neste ensaio, as avaliações foram feitas nos períodos das águas e da seca. Todavia, uma vez que os padrões de precipitação da região têm apresentado variações nos últimos anos, dificultando a caracterização dos respectivos períodos, optou-se por caracterizar os períodos das águas e da seca de acordo com as condições climáticas regionais.

As diferentes estratégias de fornecimento do suplemento no período das águas 2003 (21/01/03 a 13/05/03) constituíram os seguintes tratamentos:

- tratamento SD - suplementação diária;

- tratamento DA - suplementação em dias alternados (dia sim e dia não)

- tratamento SF - suplementação oferecida de segunda a sexta-feira com suspensão aos sábados e domingos.

Os animais dos tratamentos DA e SF (que não eram suplementados todos os dias) receberam o mesmo manejo e foram mantidos em baias individuais sem qualquer tipo de suplementação pela manhã, sendo soltos com os demais. O suplemento fornecido no período de janeiro a maio de 2003 foi constituído de $0,4 \mathrm{~kg}$ de glúten de milho-60 e $0,1 \mathrm{~kg}$ de levedura e oferecido na proporção de $5 \mathrm{~kg}$ de concentrado/ animal/dia. O concentrado foi oferecido aos animais da seguinte forma: $0,5 \mathrm{~kg}$ diariamente; $1,0 \mathrm{~kg}$ (dobro) em dias alternados; e $0,5 \mathrm{~kg}$ de segunda a quinta-feira e $1,5 \mathrm{~kg}$ na sexta-feira (triplo) nos tratamentos SD, DA e SF, respectivamente. Assim, todos os animais receberam, em média, $0,5 \mathrm{~kg}$ de concentrado/dia.

A suplementação foi feita com o mínimo de concentrado, com ênfase em proteína de escape, sendo utilizado o glúten de milho-60, cuja eficiência de utilização foi demonstrada por Costa (2001), que utilizou glúten de milho-60 em proporções de 300 a 400 g/animal/dia. A levedura, que possui características que contribuem para melhor atividade microbiana, foi utilizada como palatabilizante, visto que o glúten de milho-60 é de baixa aceitabilidade.

No período da seca (13/05 a 25/11/03), utilizou-se o suplemento composto de milho, farelo de soja e uréia, oferecido na quantidade de $1 \%$ do PV. No início da seca (maio a agosto), considerando que na transição águas-seca a forragem apresentava aproximadamente 6\% de PB (na MS), foi fornecido um suplemento com $18 \% \mathrm{~PB}$, composto de $0,064 \mathrm{~kg}$ de farelo de soja, $0,911 \mathrm{~kg}$ de milho e $0,025 \mathrm{~kg}$ de uréia para cada quilograma de concentrado e, ao final da 
seca (setembro a novembro), como a forragem apresentava aproximadamente $4 \% \mathrm{~PB}$, o suplemento foi composto de $0,145 \mathrm{~kg}$ de farelo de soja, $0,830 \mathrm{~kg}$ de milho e $0,025 \mathrm{~kg}$ de uréia para cada quilograma de concentrado.

Em virtude da grande quantidade de suplemento fornecido ( $1 \%$ do PV), houve alteração na forma de fornecimento aos animais nesse período, sendo adotadas diferentes estratégias conforme os tratamentos estabelecidos:

- tratamento SD - suplementação diária;

- tratamento DA - quantidade semanal de suplemento dividida uniformemente por quatro dias e oferecida em dias alternados (dia sim e dia não), sendo a quantidade semanal igual à do tratamento SD;

- tratamento SF - quantidade semanal de suplemento dividida uniformemente por cinco dias e oferecida de segunda a sexta-feira com suspensão aos sábados e domingos, sendo a quantidade semanal igual à do tratamento SD.

A avaliação do período das águas foi realizada no período de novembro de 2003 a fevereiro de 2004. O suplemento foi composto de $87,5 \%$ de milho e $12,5 \%$ glúten de milho-60 e fornecido em quantidades préestabelecidas de $2,0 \mathrm{~kg} / \mathrm{animal} / \mathrm{dia}$. A estratégia utilizada para fornecimento do suplemento foi igual à do período da seca, quando os animais receberam semanalmente $14,0 \mathrm{~kg}$ de concentrado. Os animais do tratamento SD (suplementação diária), DA (suplementação em dias alternados) e SF (suplementação suspensa aos sábados e domingos) receberam 2,0;3,5 e 2,8 kg concentrado/animal/ dia, respectivamente.

A composição bromatológica dos ingredientes utilizados na formulação dos suplementos é descrita na Tabela 2.

O período de ocupação nos piquetes foi variável, ou seja, a mudança de piquete foi realizada conforme a observação do

Tabela 2 - Composição bromatológica dos ingredientes utilizados no suplemento

Table 2 - Chemical composition of the ingredients used in the concentrate

\begin{tabular}{lccccc}
\hline & \multicolumn{5}{c}{$\begin{array}{c}\text { Ingrediente } \\
\text { Ingredient }\end{array}$} \\
\cline { 2 - 6 } & MI & SF & LEV & GMI & UR \\
& COR & $S M$ & YEAST & $C G$ & $U R$ \\
\hline MS (\%) & 89,29 & 90,40 & 89,47 & 91,00 & 98,00 \\
$D M(\%)$ & 10,00 & 50,00 & 42,30 & 63,23 & 281,00 \\
PB (\%MS) & & & & & \\
$C P(\% D M)$ & 4,80 & 2,00 & 0,20 & 3,20 & - \\
EE (\%MS) & 19,75 & 15,00 & 2,49 & 7,57 & - \\
$E E(\% D M)$ & & & & & \\
FDN (\%MS) & $1 \% D F(\% D M)$ & & & &
\end{tabular}

MI - milho; SF - farelo de soja; LEV - levedura; GMI - glúten de milho-60; UR - uréia.

COR - corn; SM - soybean meal; YEAST - yeast; CG - corn gluten-60; UR - urea. material verde disponível para que sempre houvesse quantidades suficientes aos animais. A taxa de lotação média foi de 1,32 UA/ha ao longo do período experimental.

Para amostrar a forragem consumida e evidenciar a seletividade pelos animais, foram feitas avaliações da forragem no pré e pós-pastejo em cada piquete experimental, comparando três métodos de amostragem: método do quadrado (disponibilidade total), pastejo simulado e extrusa. Nos métodos de pastejo simulado e extrusa, foram realizadas mais duas avaliações, considerando os grupos genéticos dos animais (Nelore e mestiços Nelore $\times$ Red Angus), totalizando cinco avaliações.

As determinações de disponibilidade de forragem foram realizadas pelo método do quadrado em todo o período experimental (janeiro de 2003 a fevereiro de 2004). Um quadrado metálico $(0,7 \times 0,7 \mathrm{~m})$ foi lançado ao acaso cinco vezes por piquete, sendo o corte efetuado a $25 \mathrm{~cm}$ de altura do solo no pré e pós-pastejo, em cada piquete, para composição de uma amostra composta.

O pastejo simulado foi realizado conforme metodologia descrita por Johnson (1978), ao mesmo tempo em que se realizou a coleta de extrusa, sendo observados, além do comportamento de pastejo dos animais, área, altura e partes da planta que estavam sendo consumidas. As amostras foram coletadas sempre pelo mesmo observador para cada animal, na tentativa de se obter uma porção da planta similar àquela selecionada pelos animais.

A coleta de extrusa foi feita segundo procedimentos descritos por McMeniman (1997), utilizando-se dois animais machos castrados (24 meses de idade e $430 \mathrm{~kg}$ de PV) fistulados no esôfago, um da raça Nelore e outro mestiço (cruzamento industrial Nelore x Red Angus). Os mesmos animais foram utilizados para amostrar todos os piquetes.

As análises bromatológicas das amostras de forragem e concentrado foram realizadas no Laboratório de Nutrição Animal pertencente ao Departamento de Zootecnia. Foram determinados os teores MS e PB, conforme técnicas descritas por Silva (1990), e os de FDN e FDA, segundo Van Soest et al. (1991).

O delineamento experimental adotado foi o inteiramente casualizado, com três tratamentos, em que cada tratamento foi constituído de oito repetições, considerando cada animal uma repetição. Além do efeito de tratamento, também foram testados o efeito do período do ano e a interação tratamento $\times$ período, porém, como a interação não foi significativa, foi removida do modelo. Os dados foram submetidos à análise de variância por meio do teste $\mathrm{F}$ e as médias comparadas pelo teste Tukey a 5\% de significância. A análise estatística foi realizada por meio do programa Statistical Analysis System (S AS, 1993). 


\section{Resultados e Discussão}

Os dados referentes à disponibilidade e ao valor nutritivo da forragem ao longo do período experimental (Tabela 3) evidenciaram alta produção de MS do capim-braquiária, como resultado do manejo adotado. Ressalta-se que, durante o período das águas de 2003, utilizou-se taxa de lotação de 1,00 UA/ha, o que propiciou alta oferta de forragem no período seco subseqüente (Tabela 3).

Fernandes et al. (2005) evidenciaram a alta capacidade de produção dessa espécie forrageira quando submetida ao manejo adequado. Esses autores observaram em sistemas de pastejo rotacionado disponibilidade de MS com resíduo pós-pastejo de $25 \mathrm{~cm}$ durante o período das águas (199 dias) de 23,3 t/ha com 28 dias de descanso e 3,5 dias de ocupação de cada piquete e adubações de manutenção sempre após a saída dos animais do piquete.

Nas amostras colhidas por meio de pastejo simulado, foram obtidos 13,$1 ; 10,28$ e de $9,52 \%$ de PB nas colheitas realizadas nos períodos das águas e de seca de 2003 e águas de 2004, respectivamente.

O manejo da pastagem com baixa lotação nas águas de 2003 levou ao acúmulo de forragem (6,99 t/ha). Portanto, no período seco havia alta oferta de folhas e, por meio do pastejo simulado, obtiveram-se amostras com alto teor de PB $(10,28 \%)$ e baixo de FDN $(55,06 \%)$. No período das águas subseqüente, no entanto, a forragem disponível apresentava $9,52 \%$ de PB e valor de FDN mais alto $(62,54 \%)$, em decorrência do acúmulo de caule e de material morto. Esses resultados foram semelhantes aos obtidos por Freitas (2005), em ensaios de pastejo com essa espécie forrageira.

Tabela 3 - Valor nutritivo da forragem, disponibilidade média de matéria seca (DMS) e taxa de lotação (UA/ha) ao longo dos períodos do ano

Table 3 - Chemical composition of the forage, mean dry matter availability $(A D M)$, and stocking rate $(A U / h a)$ in different seasons

\begin{tabular}{lccc}
\hline & \multicolumn{3}{c}{$\begin{array}{c}\text { Período } \\
\text { Season }\end{array}$} \\
\cline { 2 - 4 } & $\begin{array}{c}\text { Águas 2003 } \\
\text { Rainy 2003 }\end{array}$ & $\begin{array}{c}\text { Seca 2003 } \\
\text { Dry 2003 }\end{array}$ & $\begin{array}{c}\text { Águas 2004 } \\
\text { Rainy 2004 }\end{array}$ \\
\hline $\begin{array}{l}\text { MS \% } \\
D M \%\end{array}$ & 27,26 & 27,94 & 26,01 \\
PB (\%MS) & & & \\
$C P(\%$ DM) & 13,10 & 10,28 & 9,52 \\
FDN (\%MS) & & & \\
$N D F(\% D M)$ & 62,58 & 55,06 & 62,54 \\
FDA (\%MS) & & & \\
ADF (\% DM) & & 29,23 & 31,53 \\
$\begin{array}{l}\text { DMS (t/ha) } \\
\text { ADM (t/ha) }\end{array}$ & 33,08 & 6,99 & 7,83 \\
$\begin{array}{l}\text { Taxa de lotação (UA/ha) } \\
\text { Stocking rate (AU/ha) }\end{array}$ & 1,00 & 1,35 & 1,62 \\
\hline
\end{tabular}

No período das águas (em 2003 e 2004), foram oferecidas quantidades fixas de 0,50 e $2,00 \mathrm{~kg}$ de concentrado/ animal/dia, respectivamente. Mesmo no período da seca, quando o concentrado foi fornecido em quantidades maiores (1\% PV, média de 3,54 kg de concentrado/animal/dia), o consumo de concentrado foi semelhante (Tabela 4) e não diferiu significativamente $(\mathrm{P}>0,05)$ entre os tratamentos $(\mathrm{P}>0,05)$ nos períodos analisados.

O suplemento oferecido no período das águas de 2003, composto de $90 \%$ de glúten de milho-60 e 10\% de levedura, foi fornecido em quantidade equivalente a $0,2 \%$ do PV dos animais $(0,5 \mathrm{~kg} / \mathrm{animal} / \mathrm{dia})$, como fonte protéica de baixa degradabilidade ruminal e baixo consumo para maximizar a utilização da proteína solúvel da pastagem, que apresentou, em média, $13,1 \%$ de PB.

No período seco do ano, a forragem geralmente é de baixa qualidade e apresenta menos que 7\% de PB na MS, além de menor solubilidade, havendo, portanto, deficiência de proteína degradável no rúmen para crescimento microbiano e atividade fermentativa adequada, tornando necessária a suplementação. Portanto, nesse período, foi utilizado um suplemento com alto teor protéico, composto de milho, farelo de soja e uréia (nitrogênio não-protéico), potencialmente aproveitáveis pelos ruminantes, fornecido na quantidade de $1 \%$ do peso vivo animal. No período das águas subseqüente (2004), uma vez que a qualidade da forragem deveria ser superior, o suplemento oferecido foi composto de milho $(87,5 \%)$ e glúten de milho-60 $(12,5 \%)$ e fornecido na proporção de $0,6 \%$ do PV, quantidade superior à do período das águas de 2003 e inferior à do período da seca. A forragem apresentou, no entanto, teor de PB inferior $(9,52 \%)$ se comparado ao dos demais períodos e não estava totalmente disponível. Esse efeito levou ao acúmulo de forragem de pior qualidade, como resultado do manejo da forragem (baixa taxa de lotação), ocasionando dificuldade de rebrota, decorrente do resíduo acumulado nas secas.

O consumo de forragem foi estimado considerando as exigências descritas pelo NRC (1984) e o consumo de concentrado e a estimativa do valor energético da forragem (NDT), segundo Weiss et al. (1992), obtendo-se consumo de 2,39\% PV no período das águas de 2003 com 59,33\% de NDT, superiores aos encontrados por Zervoudakis et al. (2004) para o consumo de forragem por bovinos mestiços em pastagem de Brachiaria decumbens sob suplementação com 1,93\% do PV. Esses autores observaram influência positiva da suplementação sobre os consumos de MS e MO, que foram 18 e $19 \%$ superiores aos obtidos nos animais controle, justificando os melhores desempenhos dos animais sob suplementação. 
Tabela 4 - Quantidade de concentrado oferecida e consumida durante os períodos de avaliação Table 4 - Amount of concentrate fed and ingested on each treatment in the different seasons

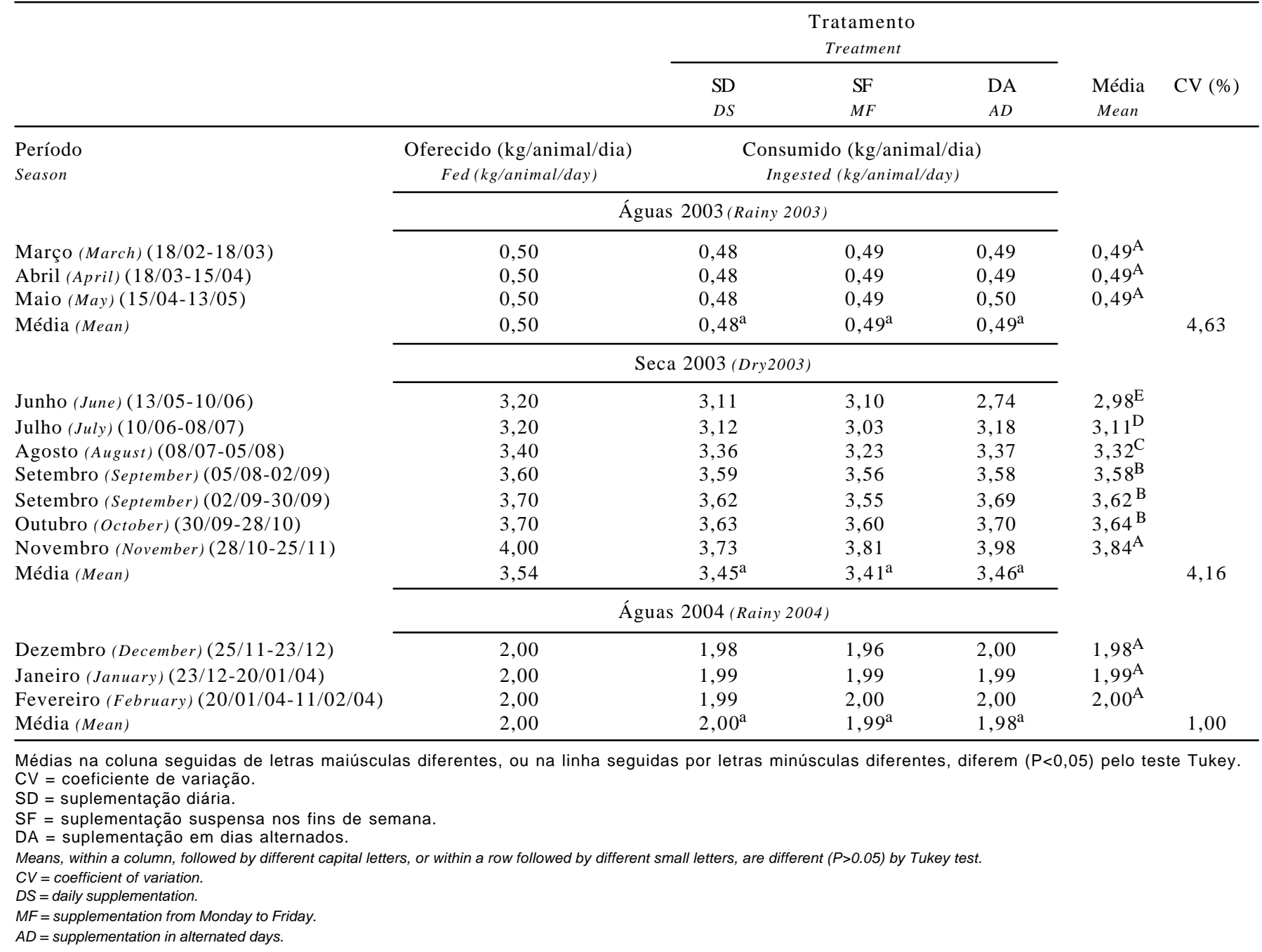

As características qualiquantitativas da pastagem afetaram significativamente as respostas à suplementação ao longo do período experimental (Tabela 5). Os valores referentes ao ganho médio diário (GMD) nos diferentes tratamentos, em todos períodos experimentais, não foram influenciados significativamente $(\mathrm{P}>0,05)$ pela interação período $\times$ tratamento, contudo, ao analisar os dados de subperíodo, verificou-se resposta acentuada no ganho de peso.

Durante o período das águas de 2003, as médias dos ganhos de peso $(\mathrm{kg} / \mathrm{dia})$ nos tratamentos $\mathrm{SD}$, DA e SF foram de 0,$76 ; 0,71$ e $0,74 \mathrm{~kg} / \mathrm{dia}$ (Tabela 5), respectivamente, não apontando diferenças significativas $(\mathrm{P}>0,05)$. Os resultados foram semelhantes aos encontrados por Farmer et al. (2001), que, avaliando quatro frequiências de suplementação (2, 3, 5 e 7 dias/semana), concluíram que a eficiência de utilização da forragem melhorou com o aumento da freqüência, mas o desempenho dos animais não apresentou diferença significativa.
Zervoudakis et al. (2001) estudaram o desempenho de bovinos mestiços Holandês-Zebu sob suplementação durante o período das águas mantidos em pastagem de Brachiaria decumbens e verificaram ganhos de peso de $0,88 \mathrm{~kg}$ naqueles sem suplementação; de $0,93 \mathrm{~kg}$ naqueles sob suplementação com concentrado à base de milho e farelo de soja; e de 1,04 e 1,01 kg naqueles sob suplementação com concentrado à base de farelo de trigo e farelo de soja nas proporções de 1 e $2 \mathrm{~kg}$ de suplemento/animal, respectivamente. Neto et al. (2005), no entanto, ao estudarem o desempenho de novilhos recriados em pastagem de capim Panicummaximum cv. Tanzânia submetidos a diferentes freqüências de suplementação, verificaram efeito da suplementação sobre o desempenho dos animais $(\mathrm{P}<0,05)$, mas não notaram diferenças significativas $(P>0,05)$ no desempenho dos animais submetidos às diferentes freqüências de suplementação. Esses autores observaram ganhos médios diários de 0,$867 ; 0,796$ e $0,771 \mathrm{~kg} /$ dia para 
Tabela 5 - Ganhos médios diários (kg/dia) entre os tratamentos, nos diferentes períodos do ano, e peso médio final (kg) em cada período Table 5 - Average daily weight gain ( $\mathrm{kg} /$ day) in function of treatments, season, and final weight $(\mathrm{kg})$ in each period

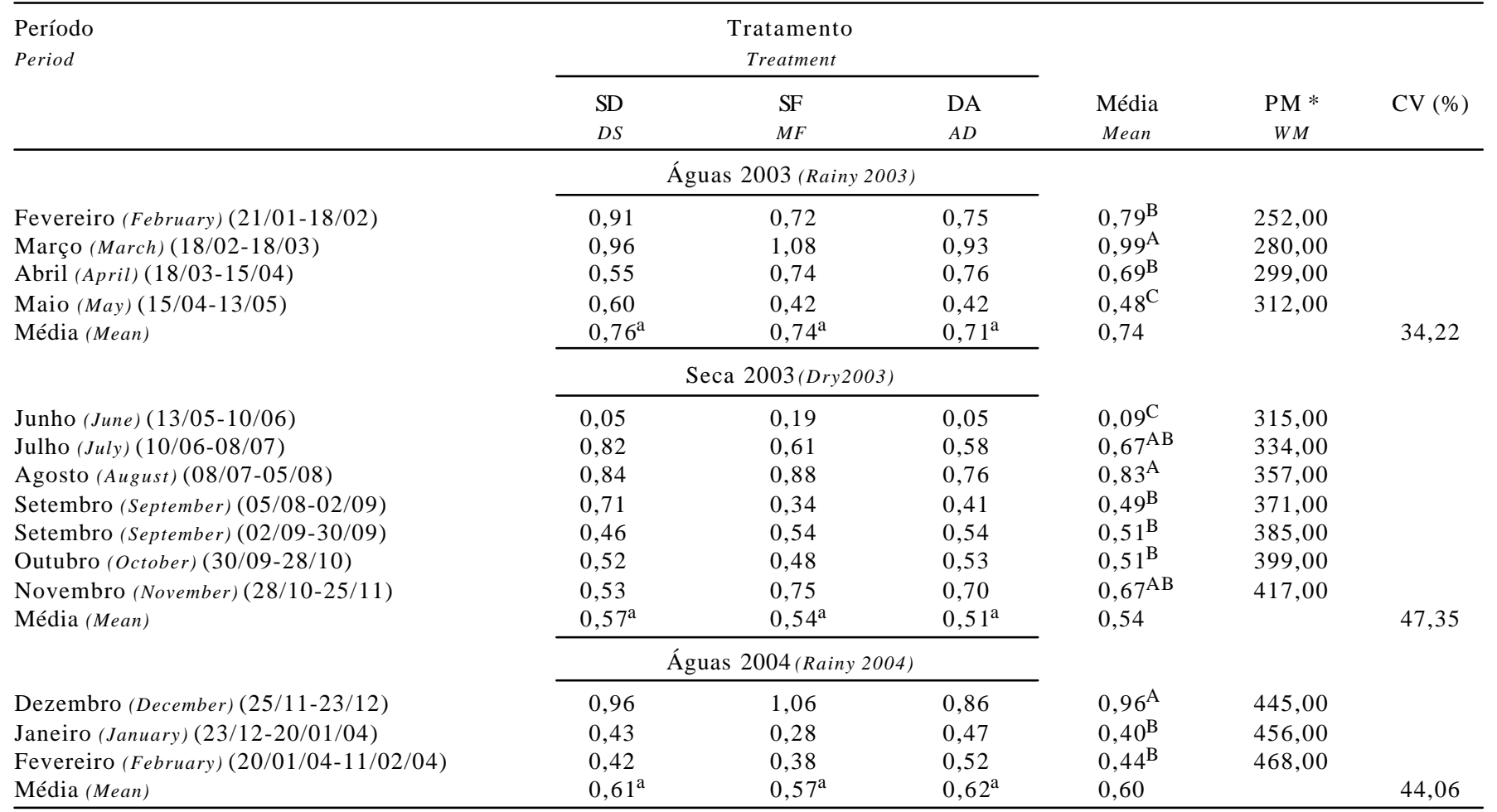

Médias na coluna seguidas de letras maiúsculas diferentes, ou na linha seguidas por letras minúsculas diferentes são diferentes (P<0,05) pelo teste Tukey. $\mathrm{CV}=$ coeficiente de variação.

SD = suplementação diária.

SF = suplementação oferecida de segunda à sexta-feira e suspensa aos sábados e domingo,

$\mathrm{DA}=$ suplementação em dias alternados

*PM: peso médio dos animais no final de cada período de 28 dias.

Means, within a column, followed by different capital letters, or within a row followed by different small letters, are different $(P>0.05)$ by Tukey test.

$\mathrm{CV}=$ coefficient of variation

$D S=$ daily supplementation.

$M F=$ supplementation from Monday to Friday

$A D=$ supplementation in alternated days.

${ }^{*}$ WM: Animals average weight obtained at the end of each 28 days period.

suplementação diária, três e duas vezes por semana com suplemento à base de mistura mineral, farelo de soja, casca do grão de soja e milho em grão moído, fornecidos em quantidades equivalentes a $0,2 \% \mathrm{PV} / \mathrm{dia}$. De modo semelhante, Moraes et al. (2005) avaliaram diferentes frequiências de suplementação durante o período das águas com concentrado à base de farelo de soja e mistura mineral na proporção de $0,50 \mathrm{~kg} /$ animal/dia e também não observaram diferenças $(\mathrm{P}>0,10)$ entre as diferentes freqüências, observando ganhos médios diários de 0,895; 0,885 e $0,892 \mathrm{~kg} / \mathrm{dia}$, respectivamente, para os animais sob suplementação $3,5 \mathrm{e}$ 7 vezes/semana.

Durante o período das águas de 2003, verificaram-se menores ganhos no mês de maio (Tabela 5), em decorrência do início do período seco, com baixa precipitação (Tabela 1), o que resultou em decréscimo no valor nutritivo da forragem.

De acordo com o sistema Cornell Net Carbohydrate and Protein System (CNCPS), a proteína contida nos alimentos pode ser dividida em cinco frações: A - totalmente solúvel no rúmen, constituída de nitrogênio não-protéico; $\mathrm{B}_{1}, \mathrm{~B}_{2}$ e $\mathrm{B}_{3}$-proteínas verdadeiras, de degradação ruminal rápida, intermediária e lenta, respectivamente; e fração $C$ - insolúvel no rúmen. Os teores das frações $\mathrm{A}, \mathrm{B}_{1}$ e $\mathrm{B}_{2}$ decrescem conforme aumenta a idade da planta, assim, a utilização de um suplemento com alta proporção de proteína de baixa degradação ruminal pode diminuir a síntese de proteína microbiana e a digestão da fração fibrosa, em virtude da quantidade inadequada de nitrogênio e proteína degradável no rúmen. Portanto, é necessário o suprimento de proteína degradável no rúmen em combinação à de baixa degradação ruminal nos animais mantidos em pastagens de gramíneas de clima tropical (Anderson, 2000).

Verifica-se na Tabela 5 que, no primeiro subperíodo do período da seca (junho), os GMD foram reduzidos bruscamente, pois o ganho de peso de muitos animais diminuiu, provavelmente em virtude da alteração na quantidade de suplemento oferecido ( $1 \% \mathrm{PV})$ e da qualidade da forragem. Em junho, observou-se menor consumo do suplemento, 
médias de 2,98 kg/dia (Tabela 4), em relação aos subperíodos subseqüentes na seca, em decorrência da adaptação dos animais às quantidades oferecidas (1\% PV). Além disso, pode ter ocorrido diminuição no consumo de MS da forragem, ocasionada pelo efeito substitutivo do fornecimento do suplemento.

Nos dois subperíodos subseqüentes (julho e agosto), houve aumento significativo no consumo do suplemento (Tabela 4) e no ganho de peso (Tabela 5), provavelmente em virtude do ganho compensatório, e posterior estabilização do ganho de peso.

Com base no NRC (1984), no consumo de concentrado e na estimativa do valor energético da forragem (NDT), segundo Weiss et al. (1992), calculou-se o consumo de forragem no período seco $(60,42 \%$ de NDT) e determinou-se o valor estimado de $0,83 \% \mathrm{PV}$.

Durante o período da seca pode ter ocorrido efeito substitutivo, decorrente da elevada disponibilidade de forragem (aproximadamente 7,0 t/ha), associada ao seu valor nutritivo, avaliado em amostras obtidas por meio do pastejo simulado (10\% PB, 55,06\% de FDN e $29,23 \%$ de FDA). Os dados das Tabelas 3, 4 e 5 sugerem que os animais foram mais seletivos nesse período, ocasionando decréscimo no consumo de forragem em relação ao de suplemento.

Em revisão sobre teores de $\mathrm{PB}$ e proteína de escape de gramíneas forrageiras, Reis et al. (2004) observaram que gramíneas de clima tropical $\left(\mathrm{C}_{4}\right)$, comparadas às de clima temperado $\left(C_{3}\right)$, apresentaram maior proporção de proteína de escape, expressa em porcentagem da proteína total. Essas diferenças relativas à alta proporção de proteína que escapa à degradação ruminal nas espécies de clima tropical referem-se à localização dessa fração da proteína na bainha do feixe vascular, a qual sabidamente apresenta baixa taxa de degradação (Wilson, 1993, 1997). Assim, pode-se assumir que a presença de proteína de escape na forragem não é o fator mais importante para a atividade dos microrganismos do rúmen, podendo ocorrer limitações de proteína degradável no rúmen nos animais mantidos em pastagens de gramíneas de clima tropical.

Os dados de literatura sobre os efeitos da suplementação durante o período seco evidenciam a eficiência dessa estratégia. Moraes et al. (2004) avaliaram o efeito da frequiência da suplementação 7, 6, 5 e 3 vezes por semana sobre o desempenho de bovinos (nelorados e mestiços leiteiros) em pastagem de Brachiaria decumbens no período seco e não observaram diferença significativa no GMD entre as frequiências estudadas, porém, obtiveram valores médios inferiores $(0,25 \mathrm{~kg} / \mathrm{dia})$ aos encontrados neste estudo para todos os tratamentos, possivelmente em virtude da baixa disponibilidade $(1,1 \mathrm{t} \mathrm{MS} / \mathrm{ha})$ e qualidade da forragem, afetando negativamente o desempenho dos animais.

Góes et al. (2004), encontraram valores semelhantes, em torno de 0,60 kg de GMD, em animais recebendo $0,4 \mathrm{~kg} / \mathrm{dia}$ de suplemento constituído de milho, farelo de soja e amiréia 180 durante o período de transição águas-seca (abril a junho) com diferentes freqüências de suplementação (diariamente, duas vezes por semana e três vezes por semana) e observaram que as diferentes frequiências não influenciaram o ganho de peso dos animais.

Os ganhos médios no final do período seco foram de $0,67 \mathrm{~kg} / \mathrm{dia}$ e, no primeiro subperíodo das águas, de $0,96 \mathrm{~kg} /$ dia, provavelmente em virtude da redução na quantidade de suplemento, e da característica do suplemento, acarretando ganhos de conteúdo digestivo pelo aumento do consumo de forragem com $64,19 \%$ de NDT, estimado em 1,35\% PV. Os ganhos nos subperíodos subseqüentes (Tabela 5) foram menores $(\mathrm{P}<0,05)$ e provavelmente foram ocasionados pelo fato de os animais já terem alcançado peso superior a $450 \mathrm{~kg}$ e elevado grau de acabamento e estarem próximos ao peso de abate.

No período das águas de 2004, os ganhos observados foram, em média, 0,$61 ; 0,62$ e $0,57 \mathrm{~kg} /$ dia nos tratamentos $\mathrm{SD}$, DA e SF, respectivamente, o que está de acordo com os valores encontrados por Goes et al. (2004), de 0,62;0,59 e $0,59 \mathrm{~kg} / \mathrm{dia}$ em novilhos suplementados diariamente, duas vezes por semana e três vezes por semana, no período de transição águas-seca.

Os resultados corroboram os observados por Beaty et al. (1994), que, testando formas de oferecimento do suplemento, diariamente ou três vezes por semana, concluíram que os animais suplementados em menor freqüência são eficientes em sustentar elevados picos de amônia mesmo em dias que não consomem o suplemento.

Segundo Bohnert et al. (2002b), os ruminantes são eficientes em manter níveis adequados de nitrogênio entre períodos de suplementação, de modo que esta manutenção do $\mathrm{N}$ pode ser atribuída a possíveis alterações na permeabilidade do trato gastrintestinal à uréia e/ou na regulação da excreção da uréia. Quando recebem suplementação com proteína degradável no rúmen e proteína não-degradável no rúmen em intervalos não freqüentes, os ruminantes mantêm o ambiente produtivo para adequada digestão da fibra e cinética de fluidos de partículas.

Na Figura 1 estão apresentados os pesos dos animais durante o período experimental. $\mathrm{O}$ fornecimento de suplemento, independentemente da estratégia adotada, promoveu aumento linear no peso dos animais. A adoção desta tecnologia possibilita ganhos moderados de peso vivo e redução da idade de abate quando comparada aos sistemas 


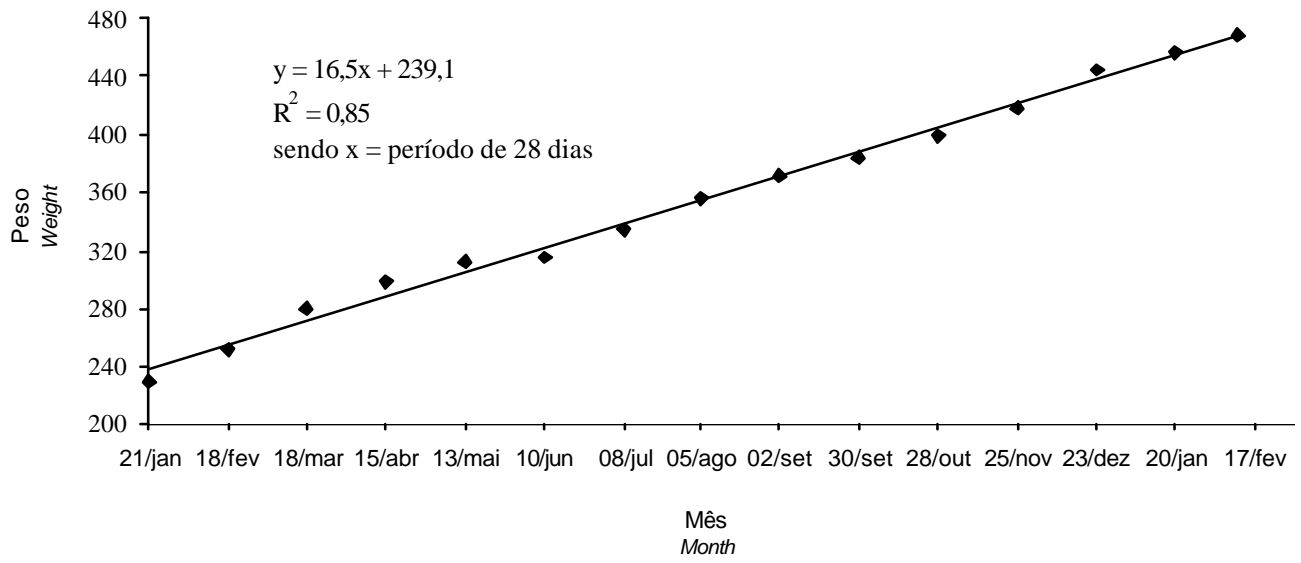

Figura 1 - Peso $(\mathrm{kg})$ dos animais ao longo do período experimental.

Figure 1 - Steers body weight $(\mathrm{kg})$ according to the months of experimental period.

tradicionais. Esse fato comprova que a suplementação de animais em pastagens, além de aumentar o desempenho animal, proporcionando altas produções de carne, melhora a eficiência econômica da atividade.

A estratégia de suplementação é fundamental e, mesmo quando realizada em dias alternados ou suspensa nos fins de semana, não afetou o ganho de peso médio diário, em comparação à suplementação diária, e ainda reduziu custos e possíveis problemas relacionados à legislação trabalhista.

\section{Conclusões}

O uso da suplementação melhorou o desempenho de bovinos mestiços mantidos em pastagens de Brachiaria brizantha cv. Marandu. A redução na freqüência de suplementação não influenciou significativamente o desempenho do animal, podendo representar uma opção para o produtor visando principalmente à redução dos custos do fornecimento da alimentação.

\section{Literatura Citada}

ANDERSON, B.E. Use of warm-season grasses by grazing livestock. In: MOORE, K.J.; ANDERSON, B.E. (Eds.) Native warmseason grasses: research trends and tissues. Madison: Crop Science Society of America, 2000. p.147-157. (Special Publication, 30).

BEATY, J.L.; COCHRAN, R.C.; LINTZENICH, B.A. et al. Effect of frequency of supplementation and protein concentration in supplements on performance and digestion characteristics of beef cattle consuming low-quality forages. Journal of Animal Science, v.72, n.9, p.2475-2486, 1994.

BOHNERT, D.W.; SHAUER, C.S.; BAUER, M.L. et al. Influence of rumen protein degradability and supplementation frequency on steers consuming low-quality forage: cow performance and efficiency of nitrogen use in wethers. Journal of Animal Science, v.80, p.1629-1637, 2002a.
BOHNERT, D.W.; SHAUER, C.S.; BAUER, M.L. et al. Influence of rumen protein degradability and supplementation frequency on steers consuming low-quality forage: site of digestion microbial efficiency. Journal of Animal Science, v.80, p.2967-2977, 2002b.

BRITO, R.M. Valor econômico da suplementação alimentar para bovinos em pastagens de Brachiaria brizantha cv. Marandu. Jaboticabal: Universidade Estadual Paulista, 2004. 90p. Tese (Doutorado em Zootecnia) - Universidade Estadual Paulista, 2004

CANESIN, R.C.; FATURI, C.; BERCHIELLI, T.T. et al. Características quantitativas da carcaça de bovinos a pasto submetidos a diferentes estratégias de suplementação. In: REUNIÃO ANUAL DA SOCIEDADE BRASILEIRA DE ZOOTECNIA, 41., 2004, Campo Grande. Anais... Campo Grande: Sociedade Brasileira de Zootecnia, 2004. (CD-ROM).

COSTA, R.M. Avaliação de suplementos com proteína degradável e de escape ruminal para recria de bovinos. Jaboticabal: Universidade Estadual Paulista, 2001. 47p. Dissertação (Mestrado em Zootecnia) - Universidade Estadual Paulista, 2001.

FARMER, C.G.; COCHRAN, R.C.; SIMMS, D.D. et al. The effects of several supplementation frequencies on forage use and performance of beef cattle consuming dormant tallgrass prairie forage. Journal of Animal Science, v.79, n.6, p.2276-2285, 2001.

FERNANDES, L.O.; REIS, R.A.; PAES, J.M.V. et al. Suplementação de bovinos de corte durante o período das águas manejados em sistema de pastejo rotacionado. In: REUNIÃO ANUAL DA SOCIEDADE BRASILEIRA DE ZOOTECNIA, 42., 2005, Goiânia. Anais... Goiânia: Sociedade Brasileira de Zootecnia, 2005. (CD-ROM).

FREITAS, D. Suplementação da dieta de novilhos de três grupos genéticos em pastagem de Brachiaria brizantha cv. Marandu. Jaboticabal: Universidade Estadual Paulista, 2005. 85p. Tese (Doutorado em Zootecnia) - Universidade Estadual Paulista, 2005.

GÓES, R.H.T.B.; MÂNCIO, A.B.; LEÃO, M.I. et al. Efeito da freqüência da suplementação no desempenho de novilhos Nelore recriados em pasto de Brachiaria brizanta, na região Amazônica. In: REUNIÃO ANUAL DA SOCIEDADE BRASILEIRA DE ZOOTECnIA, 41., 2004, Campo Grande. Anais... Campo Grande: Sociedade Brasileira de Zootecnia, 2004. (CD-ROM).

JOHNSON, A.D. Sample preparation and chemical analysis of vegetation. In: t'MANEJET, L. (Ed.). Measurement of grassland vegetation and animal production. Aberustwysth: Commonwealth Agricultural Bureaux, 1978. p.96-102. 
KREHBIEL, C.R.; FERREL, C.L.; FREETLY, H.C. Effects of frequency of supplementation on dry matter intake and net portal and hepatic flux of nutrients in mature ewes that consume low-quality forage. Journal of Animal Science, v.76, n.9, p.2464-2473, 1998.

McMENIMAN, N.P. Methods of estimating intake of grazing animals. Simpósio sobre tópicos especiais em zootecnia. In: REUNIÃO ANUAL DA SOCIEDADE BRASILEIRA DE ZOOTECNIA, 34., 1997, Juiz de Fora. Anais... Juiz de Fora: Sociedade Brasileira de Zootecnia, 1997. p.131-168.

MINSON, D.J. Forage in ruminant nutrition. New York: Academic Press, 1990. 483p.

MORAES, E.H.T.B.; PAULINO, M.F.; FIGUEIREDO, D.M. et al. Desempenho de novilhos de corte submetidos a diferentes freqüências de suplementação durante o período das águas. In: REUNIÃO ANUAL DA SOCIEDADE BRASILEIRA DE ZOOTECNIA, 42., 2005, Goiânia. Anais... Goiânia: Sociedade Brasileira de Zootecnia, 2005. (CD-ROM).

MORAES, E.H.T.B.; PAULINO, M.F.; FIGUEIREDO, D.M. et al. Efeito da freqüência da suplementação no desempenho de bovinos de corte sob pastejo no período seco do ano. In: REUNIÃO ANUAL DA SOCIEDADE BRASILEIRA DE ZootecniA, 41., 2004, Campo Grande. Anais... Campo Grande: Sociedade Brasileira de Zootecnia, 2004. (CD-ROM).

NATIONAL RESEARCH COUNCIL - NRC. Nutrient requirements of beef cattle. 6.ed. Washington D.C.: National Academy Press, 1984. 90p

NET O,A.P.; ZERVOUDAKIS, J.T.; CABRAL, L.S. et al. Freqüência de suplementação de bovinos nelore durante o período das águas: desempenho. In: REUNIÃO ANUAL DA SOCIEDADE BRASILEIRA DE ZOOTECNIA, 42., 2005, Goiânia. Anais... Goiânia: Sociedade Brasileira de Zootecnia, 2005. (CD-ROM).

PAULINO, M.F. Estratégias de suplementação para bovinos em pastejo. In: SIMPÓSIO DE PRODUÇÃO DE GADO DE CORTE, 1., 2001, Viçosa, MG. Anais... Viçosa, MG: Universidade Federal de Viçosa, 2001. p.137-156.

REIS, R.A.; BERTIPAGLIA, L.M.A; FREITAS, D. et al. Suplementação protéica energética e mineral em sistemas de produção de gado de corte nas águas e nas secas. In: SANTOS, F.A.P.; MOURA, J.C.; FARIA, V.P. et al. (Eds.) Pecuária de corte intensiva nos trópicos. 1.ed. Piracicaba: Fundação de Estudos Agrários Luiz de Queiroz, 2004. v.1, p.171-226.

REIS, R.A.; RODRIGUES, L.R.A.; PEREIRA, J.R.A. A suplementação como estratégia de manejo da pastagem. In: SIMPÓSIO SOBRE MANEJO DA PASTAGEM, 13., 1997, Piracicaba. Anais... Piracicaba: Fundação de Estudos Agrários Luiz de Queiroz, 1997. p.123-150.

SATTER, S.D.; SLYTER, L.L. Effects of ammonia concentration on rumen microbial protein production "in vitro". British Journal of Nutrition, v.32, p.245-249, 1974.
STATISTICAL ANALYSIS SYSTEMS - SAS. SAS/STAT user's guide: statistics. 4.ed. Version 6, Cary: 1993. 943p.

SIEBERT, B.D.; HUNTER, R.A. Supplementary feeding of grazing animals. In: HACKER, J.B. (Ed). Nutritional limits to animal production from pasture. Farnham Royal: Commonwealth Agricultural Bureau, 1982. p.409-425.

SILVA, D.J. Análise de alimentos: métodos químicos e biológicos. Viçosa, MG: Universidade Federal de Viçosa, 1990. 165p.

Van SOEST, P.J.; ROBERTSON, J.B.; LEWIS, B.A. Methods for dietary fiber, and nonstarch polysaccharides in relation to animal nutrition. Journal of Dairy Science, v.74, n. 10, p.3583-3597, 1991.

WEISS, W.P.; CONRAD, H.R.; PIERRE, N.R. A theorically-based model for predicting total digestive nutrient values of forage and concentrates. Animal Feed Science and Technology, v.39, n.1, p.95-110, 1992.

WILSON, J.R. Organization of plant tissues. In: JUNG, H.G.; BUXTON, D.R.; HATFIELD, R.D. et al. (Eds.). Forage cell wall structure and digestibility. Madison: ASA, CSSA, SSSA, 1993. p.1-32.

WILSON, J.R. Structural and anatomical traits of forages influencing their nutritive value for ruminants. In: INTERNATIONAL SYMPOSIUM ON ANIMAL PRODUCTION UNDER GRAZING, 1997, Viçosa, MG. Proceedings... Viçosa, MG: Universidade Federal de Viçosa, 1997. p.173-208.

ZERVOUDAKIS, J.T. Desempenho, características de carcaça e exigências líquidas de proteína e energia de novilhos suplementados no período das águas. 2000. 84p. Viçosa, MG: Universidade Federal de Viçosa, 2000. 78p. Dissertação (Mestrado em Zootecnia) - Universidade Federal de Viçosa, 2000.

ZERVOUDAKIS, J.T.; PAULINO, M.F.; DETMANN, E. et al. Suplementos múltiplos para recria de novilhos durante o período transição águas-seca: consumo e taxa de passagem. In: REUNIÃO ANUAL DA SOCIEDADE BRASILEIRA DE ZOOTECNIA, 41., 2004, Campo Grande. Anais... Campo Grande: Sociedade Brasileira de Zootecnia, 2004. (CD-ROM).

ZERVOUDAKIS, J.T.; PAULINO, M.F.; DETMANN, E. et al. Desempenho e características da carcaça de novilhos suplementados no período das águas. Revista Brasileira de Zootecnia, v.30, n.4, p.1381-1389, 2001.

ZERVOUDAKIS, J.T.; PAULINO, M.F.; DETMANN, E. et al. Desempenho de novilhas mestiças e parâmetros ruminais em novilhos, suplementados durante o período das águas. Revista Brasileira de Zootecnia, v.31, n.2, p.1050-1058, 2002.

Recebido: 01/11/05 Aprovado: 26/10/06 